of the toxin or toxins. With regard to the second part, which ascribes to acid intoxication the symptoms of the condition, I should like to take this opportunity to say that I have long thought it untenable, and am quite prepared to accept the conclusion which Dr. Mellanby has arrived at as the result of his investigation, that cyclic romiting is in no sense an acid intoxication. The presence of the acetone series in the arine is no more than a somewhat unreliable indication of a more profound lapse from metabolic rectitude in which the diver plays the chief part.

Even in diabetic coma it is quite legitimate to donbt the importance of the acidosis, since diabetic patients will gradually sink into coma and die, even when enough alkali has been administered previously to render the urine strongly alkaline for several days before death, and experimental injection of each of the known bodies of the acetone series fails to reproduce the symptom-complex known as diabetic coma.

I am, Sir, yours faithfully,

Queen Anne-street, July 3rd, 1911. FREDERICK LANGMEAD,

\section{THE DECLINING BIRTH-RATE.}

\section{To the Editor of THE LANCET.}

SiR,-In Mr. F. E. Fremantle's Edward Jenner lecture on "The Declining Birth-rate," published in THE LANCET of April 22nd, we read (p. 1061): "The chief factors, then, in the decline of the birth-rate are mechanical and logical. The mechanical factors just named are in reality only methods. It is the following logical factors that are the ultimate cause." Mr. Fremantle then gives as the logical factors (though what he quite means to connote by "logical" is not very obvious) three conditions of married life which may be shortly summarised as: 1 . Child-bearing at long intervals in the interests of health. 2. The interferences to child-bearing caused by social or conjugal obligations. 3. The desire for economy.

Surely, to any honest and impartial student of the presentday conditions of married life the most potent cause of the decline in the birth-rate of Great Britain, except perhaps among the very rich and the very poor, is compulsory barrenness. If Mr. Fremantle will pardon me for saying so, I think he might have made his lecture more illuminating and no whit less scientific if he had first read and considered the remarkable preface to Mr. George Bernard Shaw's play Gotting Married. Therein he would have had the opportunity of learning the indubitable fact that the class of women from whom the nation has perhaps most to expecti.e., that class generally termed the "middle classes" - is from a variety of causes, all of which are fully discussed by Mr. Shaw in his inimitable style, opposed to the law which involves "the saddling of the right to a child with the obligation to become the servant of a man."

The medical profession can do all that Mr. Fremantle suggests, but until the medical profession throws its influence on the side of those who are striving to attract public attention to the lamentable state of the English marriage and divorce laws very little hope can be reasonably entertained that the fail in the birth.rate in the British Isles is going to stop. Mr. Fremantle also adrocates that all aids to the prevention of conception "should be relentlessly pursued and checked by the law." Does he propose that a married couple should cease from sexual relationship if for any reason, and indeed there are many, conception should be highly undesirable? If Mr. Fremantle does propose that, and it is difficult to construe any other meaning to his remark, does he reflect on all that is almost sure to follow upon such procedure? It is inconceivable that he should not have come across many cases of chronic mental disorder which are directly attributable to sexual repression, especially so in married persons separated from each other either through the rough calls of duty or business, as well as among men or women who have recently lost either wife or husband.

Further, I venture to believe that $\mathrm{Mr}$. Fremantle greatly overrates the disorders which are indubitably referable to the prevention of conception; the production of abortion is another thing altogether, and no doabt under this heading many disorders can be enumerated. An absolutely impartial investigation of data on the dangers attributable to the prevention of conception would lead one to suppose that there is only one serious disorder to be feared from the practice of preventing conception-i.e., hysteria in certain forms.

In conclusion, I would venture to assert that the propagation of a sound systematic instruction in sexual hygiene, coupled with a thorough revision of the laws connected with marriage and divorce, will do more to correct the decline in our birth-rate than any of the suggestions put forward by Mr. Fremantle in reference to the suppression of the mechanical means of preventing conception or the modi operandi of producing abortion.

I am, Sir, yours faithfully,

Ofen A. R. Berkeley Hili, M.A., M.B., Ch.B. Oxon. Saugor, Central Provinces, India, May 11th, 1911.

\section{AN ASTHETICS IN INTESTINAL OBSTRUC- TION : THE VALUE OF GASTRIC LAVAGE.}

To the Editor of THE LANCET.

SrR,-The possibility of immediate or gradual suffocation or of ensuing broncho.pneumonia in these cases is well known, but I have some reason to think the extent of the danger is not always realised. Unless special measures are taken there is this dilemma-that under a light anæsthesia rigidity and straining make the operation prolonged and difficult, and tongue retraction and laryngeal spasm entail asphyxia and cardiac dilatation; whilst under a deep one ejection of the stomach contents may still go on, and as cough reflex is abolished the patient is likely quietly to be drowned.

It is, of course, necessary for the anæsthetist to be very watchful, and it is the usual practice to keep the head low and on one side, with the opposite shoulder raised, the mouth open, and sponges ready. As Mr. Colt in his letter in your columns on June 17th also mentions tongue forceps, I would point out that it is a common and disastrous mistake of nurses and others to push the lower jaw forwards or pull out the tongue whilst a patient is in the act of vomiting. By so doing the natural closure of the larynx is interfered with and the risk of inhalation of fluid increased. This should not be done until ejection has ceased and after clearing the pharynx. If breathing should be dangerously arrested during ejection it would, I believe, be safer to perform laryngotomy. It would certainly be hazardous to leave a deeply anæsthetised patient in charge of a nurse under such circumstances. If the Trendelenburg position be adopted during operation flaid is apt to run down continuously, forming a pool in the pharynx, which cannot be kept clear even by frequent sponging.

Preliminary lavage of the stomach, as remarked by $\mathrm{Mr}$. Colt, often proves a failure, but I can hardly agree that if properly done it is a severe strain on the patient and causes much pharyngeal irritation. This should at least be carried out, even when vomiting has not been a marked symptom. I have recently drawn attention ${ }^{1}$ to the importance of doing so, at any rate when the operation has been concluded. Sometimes a stomach-tube may be left in and connected to a long tube for syphonage, but it may interfere with respiration or fluid may well up around it, so there is no complete security against inhalation.

In a paper contributed to one of your contemporaries in 1908 I suggested the advisability of preliminary laryngotomy or tracheotomy to obpiate these difficulties, and Dr. Dudley Buxton ${ }^{2}$ has described the method at length and urged its employment. Laryngotomy can be done very quickly under local or light anæsthesia ; it should cause little bleeding and no shock; the wound should heal in a few hours. The pharynx and upper larynx are cocainised and well packed with gauze all round the stomach-tube.

There are no further difficulties and dangers in regard to the respiration or the anæsthetisation, and the operator is not hurried and disturbed. In short, the advantages of the proceeding are as great as in such operations as removal of the tongue, and I trust it may be more generally adopted than is the case at present.

I am, Sir, yours faithfully,

Chelsea, S.W., June 19th, 1911.

J. D. MORTIMER. 